\title{
Cidadania, identidade racial e construção nacional na África do Sul*
}

Neville Alexander Tradução de Norberto Guarinello e João Henrique Costa

Observações introdutórias

Construir uma nação, ou promover a unidade nacional, um dos objetivos históricos daÁfrica do Sul pós-apartheid - uma nova comunidadehistórica que nos propusemos a construir - , traz consigo um vasto arco de questões, tais como liderança de classe, conteúdo de classe do movimento nacional (nacionalista), natureza e possibilidade de coesão social, entendimento do que seja uma política multicultural, comunicação intercultural, entre outras coisas. $\mathrm{N}$ aÁfrica do Sul pós-apartheid todas essas questões estão colocadas, mas, em virtude da relevância da clivagem racial nessa formação social, concentrar-meei na questão vital das identidades raciais e no modo como devemos lidar com elas.

O s comentários sobre a questão do "não-racialismo" feitos há cerca de dois anos pelo ministro M osiuoa Lekota trouxeram à luz a perturbadora relação entre políticas de ação afirmativa e perpetuação de identidades raciais na África do Sul pós-apartheid. Esta, a perpetuação, éuma das conseqüências não desejadas daquel as políticas, se concedermos aos seus arquitetos o benefício da dúvida, como creio que devamos.

Em vista da importância vital do tema para a consolidação e o aprofundamento do sistema democrático no qual vivemos hoje, acredito que os comentários do ministro deveriam acender um debate nacional sobre a

* Este texto é uma versão modificada da palestraproferidanaUniversidadedeFort H are, campus de East London, em 25 de março de 2006 . 
1. Categoria especifica mentesul-africana, que designa pessoas de origem mestiça ou que não se enquadram na dicotomia branco/negro (N. T.). questão do que entendemos por uma África do Sul democrática e não racial. Pois é um fato que identidades raciais, como sabemos por situações como as da Alemanha nazista, de Ruanda e muitas outras, são potencialmente genocidas.

É um lugar-comum nas ciências sociais, hoje em dia, o fato de as identidades individuais e sociais não serem "dadas", mas construídas. Em qualquer sociedade, o Estado ou, de modo mais geral, as classes dominantes possuem a prerrogativa paradigmática de estabelecer o modelo no qual se baseiam as identidades sociais, inclusive as raciais. Grupos subalternos e camadas dessas sociedades aceitam ou contestam necessariamente essas identidades ao longo do tempo. Em nosso próprio caso, exemplos recentes dessa contestação são categorias como "bantu" ou "coloured"1. D evemos nos lembrar, contudo, que, apesar de serem construídas, as identidades sociais parecem ter um valor primordial para a maioria dos indivíduos, precisamente por eles não terem consciência dos caminhos históricos, sociais e políticos pelos quais suas identidades foram construídas. Essa é, em última instância, a explicação psicológica para a bem conhecida tenacidade de tais identidades. Q ue possam ser desconstruídas e remoldadas éal go evidenciado pelo desmonte da supostamente imutável identidade "africânder" que está ocorrendo agora mesmo, diante de nossos ol hos.

No início do século XXI, é também um lugar-comum o fato de "raça" não ser uma categoria biológica válida. $N$ o entanto, étambém comumente reconhecido quea raça éuma real idade social. A África do Sul segregacionista do apartheid era, como é bem sabido, o exemplo proverbial, entre as nações, de uma sociedade racista no século XX. Era essa, e assim permanece, a razão do sentimento de esperança que se produziu em todo o mundo pela dissolução do regime do apartheid. H á ainda muitas pessoas que esperam que a "nova ordem" pós-apartheid mostre ao mundo que é possível encontrar o caminho para a realização do sonho de uma sociedade sem raças, talvez mesmo sem classes.

Política de ação afirmativa

A política de ação afirmativa, de nivelamento dos espaços do jogo social, da representatividade, ou qual quer outro nome adequado que queiramos empregar, é, a meu ver, uma das questões cruciais da nova África do Sul, não porque seja, de al gum modo, errônea, mas por suas conseqüências não intencionais. Foi conduzida por um processo extremamente elaborado 
de consultas públicas que culminaram nos seguintes corpos legislativos: 0 Public Services Act, o Employment Equity Act, o Skills D evelopment Act e o Skills D evelopment Levy Act. Todos eles, de modo louvável, estavam voltados para o imperativo da redistribuição do poder e dos recursos econômicos, sociais, culturais e políticos que constituíram a causa fundamental da luta contra o capitalismo racial em geral e contra 0 apartheid em particular. A penas reacionários e conservadores encouraçados opõem-se a esses objetivos do governo pós-apartheid. A grande maioria do povo apóiaos naturalmente.

M eu objetivo aqui não é criticar as intenções ou aspectos pontuais dessa política - ainda quepossa dizer que, pesando próse contras, do modo como foi implementada, ela beneficiesobretudo a classe média negra em ascensão e acabe aprofundando a desi gual dade de classe que herdamos em nossa sociedade. 0 verdadeiro alvo da intervenção do ministro Lekota era a perpe tuação de identidades raciais, a prática irresponsável de formadores de opinião políticos, culturais ou outros de se referirem de modo natural a "negros", "coloureds", "indianos" e "brancos" em seus discursos públicos corriqueiros, quando sabem muito bem que estão perpetuando assim as categorias raciais daÁfrica do Sul do apartheid e, querendo ou não, entrincheirando o preconceito racial. Esse discurso é inerente à legislação à qual me referi e às práticas sociais e dinâmicas intergrupais que produz ou reforça. Consideremos al guns aspectos relevantes dessa legislação em maior detalhe.

O Ato n. 55 de 1998, do Parlamento da República da África do Sul, é mais conhecido como Employment Equity Act, EEA [Lei do Emprego I gual]. A Seção 2 do Ato descreve seu propósito como sendo:

\section{[...] alcançar a igualdade nos postos de trabalho por meio:}

a) da proporção de oportunidades iguais e de tratamento justo no emprego mediante a eliminação de tratamento injusto; e

b) da implementação de medidas de ação afirmativa para compensar as desvantagens no emprego experimentadas por grupos especificamente designados, a fim de assegurar sua representação eqüitativa em todas as categorias ocupacionais e todos os níveis da força de trabalho.

A Seção 1 explica que "grupos especificamente designados" significa pessoas negras, mulheres e portadores de deficiências, e que "pessoas negras" é um termo genérico que representa "africanos", "coloureds" e "indianos". Como mostrarei na seqüência, não deixa de ser significativo que 
2.No final de 2004 ocorreu uma disputa acirrada sobre a composição da equipe de rúgbi de Springbok, que deveria realizar uma turnê ao Reino Unido e à Argentina. Os selecionadores foram acusados, entre outros pelo diretor geral do D epartamento de Esportes, de terem ignorado jogadores "africanos" ao inflarem a equipe com "coloureds" que, segundo se disse na ocasião, não eram "realmente" negros (cf. Smith, 2004).

3.C f. também Terblanche (2002, pp. 120-121). os membros das Forças Armadas da África do Sul, da Agência N acional de Informações e do Serviço Secreto da África do Sul não sejam definidos como "empregados" nos termos do Labour Relations Act (lei sobre relações de trabalho), e que, portanto, não estejam abrangidos pelo EEA. N este artigo, centro-me nos aspectos dessa política relativos às pessoas negras, embora algumas das observações feitas sejam implicitamente relevantes para o modo como a ação afirmativa afeta os outros "grupos especificamente designados". Também é necessário observar desde logo que, na prática, nos termos do EEA e de toda a legislação relevante, a distinção entre pessoas "africanas", "coloureds" ou "indianas" é mantida de modo consistente, ou seja, a noção de "povo negro" tende a ser esquecida ou manuseada apenas segundo as conveniências².

Para tornar inteligível minha crítica da política e da prática da ação afirmativa, é necessário esclarecer al guns conceitos importantes e al gumas implicações dessa política. Para começar, estabeleçamos uma distinção entre ação afirmativa e tranforformação. Se tomarmos a formulação do EEA como ponto departida, o termo "medidas deação afirmativa" refere-seàquelesatos que são "especificados para assegurar que pessoas devidamente qualificadas dos grupos designados tenham iguais oportunidades de emprego e sejam eqüitativamente representadas em todas as categorias de ocupação e níveis daforça detrabalho deum empregador específico".

U ma vez que medidas de ação afirmativa são um dos aspectos da transformação, é fácil confundi-las com o que poderíamos denominar medidas de transformação. A África do Sul é um país no qual, por definição, são necessárias medidas de transformação, mais do que medidas de ação afirmativa, a fim de produzir uma mudança social fundamental, ou uma "normalidade". O professor Sampie Terblanche, autor de uma fundamental, embora polêmica, História da desigualdade na África do Sul, afirma o seguinte sobre a EEA e as leis relacionadas:

Embora essas leis tenham, sem dúvida, ajudado a enfrentar o legado do apartheid e do racismo nos lugares de trabalho, beneficiaram apenas o pequeno burguês africano ascendente, aquele que tem emprego e é membro de um sindicato. Infelizmente, essas leis também aumentaram o custo do emprego e afetaram negativamente o potencial de crescimento da economia (Terblanche, 2002, p. 27)3.

Essa declaração tem uma implicação óbvia, a de que uma mudança social e econômica estrutural, isto é, uma transformação propriamentedita, 
éessencial para quepessoas negras possam se encontrar na posição de beneficiárias de ações afirmativas. Em um país com uma taxa de desemprego real da ordem de $50 \%$, a criação de empregos, que depende precisamente dessas mudanças estruturais, é a prioridade. $N$ esse sentido, é fal so 0 argumento do governo ou de outras personalidades políticas de que a criação de uns poucos milhares de empregos num setor específico ou a construção de alguns milhares de casas para pessoas que antes viviam em favelas sejam exemplos de "ação afirmativa" ou mesmo de "empoderamento negro". Pois é claro que o termo ação afirmativa só tem sentido no contexto de indivíduos que possuem a mesma qualificação ou especialização, no qual aqueles que "pertencem" a algum dos "grupos específicos" devem ter preferência sobre os demais.

D adas as circunstâncias da transição para uma democracia liberal na África do Sul, apenas a direita solitária opõe-se ao princípio da ação afirmativa, considerada como parte de um conjunto de estratégias e de políticas com vistas à realização do objetivo maior da reparação histórica. É fato, no entanto, que, em virtude das políticas racistas dos regimes de supremacia branca sul-africanos, ainda há, mesmo após dez anos de liberdade política, um conjunto pequeno de trabalhadores especializados e uma grande porcentagem de pessoas virtualmente incapazes de treinamento, como resultado das devastadoras políticas educacionais de "bantus" ou de outras tribos, vigentes durante 0 apartheid. Sob tais condições, é evidente que qualquer estratégia de "empoderamento" deveria priorizar a educação e a especialização, e, de fato, a legislação respectiva foi incorporada aos estatutos legais desde os anos de $1990^{4}$. M as também é fato, contudo, que houve pouco progresso a esse respeito. Em 2004, com efeito, o D epartamento do Trabal ho determinou uma revisão drástica dos SETAs (autoridades do setor educacional e de treinamento), instituições que haviam sido criadas precisamente para facilitar o programa de treinamento e especialização. Essa ação foi necessária porque, com poucas e louváveis exceções, esse tipo de abordagem revelara-se um espetacular fracasso. Embora os números sejam contestados por representantes do governo, afirma-se que há uma taxa de $90 \%$ de desistentes entre os educandos (como aprendizes ou candidatos a treinamento em especialidades) que são encaixados (recrutados) nos termos do esquema dos SETAs. As supostas atitudes dos próprios educandos são um indicativo do modo como esse esquema é apreendido por uma nova geração de jovens que possui um forte sentido de seus direitos. Segundo $C$ arol 0 'Brien, gerente de pequenas empresas na South African
4.As mais importantes dentre essas leis são 0 Skills D evelopment Act, de 1998, eo Skills D evelopment Levies Act, de 1999. 
5.Essa opinião é particularmenteincisiva à luz da visão institucional da National Skills Authority formulada em outubro de 2000, segundo a qual a obtenção deuma especialização por determinadas pessoas jovens "não diz respeito ao oferecimento de atividades suplementares que mantenham desempregados ativos por breves períodos ou ao simples atendimento de programas oferecidos por provedores de treinamento".

6. Termo deorigem ale mã que significa "raça superior" (N.T.).
C hamber of Business (Sacob), "eles encaram o aprendizado como uma etapa, enquanto procuram por outra coisa. N a Sacob descobrimos que 25\% de nossos aprendizes ocultaram ou encontraram outro trabalho... N ão há nenhum compromisso dos próprios aprendizes com os termos de seus contratos"5.

Ao mesmo tempo que o governo precisa apresentar melhoras visíveis, vemo-nos hoje, por outro lado, diante de uma África do Sul que muitas vezes se parece com um jogo de encaixar com casas redondas e peças quadradas, ou seja, as pessoas simplesmente não são adequadas aos empregos para os quais foram escolhidas. Essa éa razão pela qual Terblanche e outros economistas acreditam que a nomeação de "pessoas designadas" que são claramente inexperientes e mal treinadas provocou um desastre tanto no setor público como no corporativo. 0 dilema cruel enfrentado pelas autoridades constituídas foi definido por Adam et al.: "[0 ] esforço acelerado para enegrecer as instituições sul-africanas a todo custo significa muitas vezes a preterição ou a redução do número de funcionários públicos da velha ordem" (1997, p. 212).

Terblanche (2002, pp. 447-448) também observa que essas nomeações simbólicas estão na verdade enfraquecendo o Estado neoliberal e minimalista da África do Sul. Tudo se passa como se o governo, sem desejá-lo, estivesse afrouxando as rédeas do funcionalismo e do setor público da economia pela nomeação de pessoas "negras" menos experientes e menos capacitadas para postos de direção. Todos esses juízos, obviamente, devem ser apreendidos sobre o pano de fundo do Estado do apartheid, que também era excepcionalmente ineficiente em todos os seus departamentos e que podia compensar o desperdício, a corrupção e o roubo deslavado aumentando a opressão sobre os não-cidadãos negros em troca do benefício dos confortos e privilégios do H errenvolk ${ }^{6}$. É necessário, além disso, colocar-se a questão muito concreta de se há al guma alternativa viável no contexto de uma transição para a democracia que se insere na realidade geopolítica de um sistema mundial capitalista triunfante. $\mathrm{H}$ á poucos e preciosos membros do Gabinete, ou mesmo membros regulares do Parlamento do partido governante (ou de qual quer outro partido parlamentar), que ainda acreditam na originária al ternativa socialista que muitos deles propagavam nos anos de 1970 e 1980. Conseqüentemente, se o sistema capitalista deve ser "normalizado" na África do Sul, as atitudes correntes dos proprietários de capital e dos executivos de empreendimentos capitalistas devem mudar de modo radical eliteral. 
Isso nos conduz à questão do empoderamento negro. É essencial traçar uma distinção entreo assim chamado Empoderamento $N$ egro (EN ), especificamenteo Empoderamento Econômico dos $N$ egros (EEN ), eas ações afirmativas. Enquanto estas dizem respeito, obviamente, em primeira instância, à população trabalhadora do país, a reparação pelo EEN afeta, ao menos na prática, muito mais as classes alta e média. 0 governo sul-africano, com efeito, muitas vezes emprega os conceitos de EN eEEN como um recurso conveniente para "vender" o progresso que foi obtido como se fosse uma "transformação" séria. Com exceção do governo e dos que fazem a apologia do C ongresso $\mathrm{N}$ acional Africano, praticamentetodos na África do Sul reconhecem o fato de que apenas uma estreita camada de pessoas e, em al guns casos, um grupo específico deindivíduos influentes estão sendo "empoderados" economicamente. N os últimos meses, al guns dos membros mais à esquerda da al iança governistatêm reclamado demodo cada vez maisestridente contra o que começa a se parecer com um exemplo típico de "capitalismo decompadrio", próprio demanuais decursos deintrodução à economia? .

O sargumentos econômicos pró e contra essa versão particular do EEN , que conduziu na prática ao enriquecimento de um pequeno círculo de pessoas, muitas das quais líderes proeminentes da luta contra o apartheid, em oposição à - ou, nas versões mais benignas dessa política, juntamente com apriorização de empresas de pequeno e médio porte, criadoras de emprego, incluindo cooperativas de trabal hadores, entre a maioria desfavorecida, foram debatidoscom intensidade de modo exemplarmente democrático pelos meios de comunicação impressos e eletrônicos da África do Sul. Emerge, hoje em dia, um consenso de que a simples concessão de ações a al guns "negros" influentes por parte degrandes entidades corporativas da África do Sul ou multinacionais não é a única, e certamente não é a melhor, forma de EEN , pois fatal mente aumenta o fosso entre ricose pobres. I ronicamente, a crítica mais mordaz a esse fenômeno veio do Solidarity, o sindicato dos mineradores, antes exclusivamente branco e cujos membros estavam entre os dois principais beneficiários das políticas de reserva de emprego do apartheid. Referindo-sea al guns dos recém-enriquecidos ben eficiários da política deEEN , o porta-voz do sindicato sustenta que: "[no] seu caso específico, as desigual dadesjá foram eliminadas [...] [eque] permitir à elitenegra adquirir as ações mais baratas não erradicaráa pobreza, apenas criará novas formas de desigualdadequeampliarão o fosso entrericosepobres" (Petros, 2003, p. 4).
7.0 "Julgamento de Schabir Shaik", quedesastrosamente comprometeu a estatura ea posição políticas do então presidentedo Congresso Nacional da África do Sul, é o exemplo concreto mais notório desse fenômeno. 
8.Growth, Employment and Redistribution policy (ou política de $\mathrm{Crescimento,}$ Emprego e Redistribuição).
Em vez disso, propõe que, "em lugar de visar a uma raça em particular com a oferta de ações, estas deveriam ser dadas aos 'grupos de baixa renda'" (Petros, 2003, p. 4). A despeito de numerosas diferenças na abordagem e no posicionamento, sua crítica é endossada pela liderança do C osatu e por outras associações de trabalhadores. 0 fosso, simbolicamente importante e cada vez maior, entre "negros" ricos e "negros" pobres é um tema do qual vou tratar a partir de outra perspectiva. Jornalistas e analistas econômicos ou sociais publicaram uma série de estatísticas devastadoras que parecem confirmar essa tendência. Por razões táticas, o governo dirigido pelo Congresso $\mathrm{N}$ acional Africano teve que recuar de sua prévia defesa agressiva e de sua aliança com a política neoliberal de ajuste estrutural auto-imposto, conhecida pelo acrônimo de GEAR ${ }^{8}$. Isso envolveu também uma abordagem mais cautelosa do estímulo anterior para que negros empreendedores se enriquecessem sem quaisquer reservas ou sentimentos de culpa. 0 infame apelo da então ministra do Comércio e da Indústria, Phumzile M lambo-N gcuka, a tais indivíduos, para que não se envergonhassem de se tornar "obscenamente ricos" - ainda que, nos recônditos de sua mente, ela possa ter tido outra intenção - , manifestou uma indubitável atitude de "materialismo grosseiro, implicando no descaso pela maioria pobre do impulso pelo auto-enriquecimento de uma elite" (Adam et al., 1997, p. 201).

D eve-se observar, no entanto, que o aparecimento de uns poucos negros ricos no cenário é acentuado pela precedente escassez desses indivíduos. Pois éum fato que, mesmo em seus próprios termos de "materialismo grosseiro", a atual distribuição desi gual dos despojos do sistema capitalista entre proprietários e executivos do capital "brancos" e "negros" quase não se alterou. N yati (2004) afirma, de modo inequívoco, que:

[...] [em dez] anos de democracia sul-africana, a transformação é conspícua por sua ausência no setor privado. Profissionais negros continuam a encontrar barreiras sistemáticas em sua mobilidade ascendente... As companhias vêem a ação afirmativa como uma ameaça ao privilégio branco. Sabem que a ação afirmativa oferece aos negros o mesmo que o imerecido privilégio branco ofereceu aos brancos por décadas, uma vantagem competitiva.

D e acordo com a avaliação do próprio governo sobre o impacto de dez anos de medidas afirmativas, em 2001 apenas 13\% dos "principais executivos" e $16 \%$ dos "executivos seniores" eram negros, enquanto o crescimento 
entre os "profissionais qualificados" e os "executivos de segundo escalão" era ainda mais lento.

Isso mostra que o empoderamento no trabalho continua, mas muito lentamente. 0 progresso foi lento na ampliação da propriedadenegra. U ma estimativa recente da eqüidade negra em companhias públicas indica 9,4\% em 2002 contra 3,9\% em 1997, a partir de um patamar virtualmente nulo antes de 1994. 0 número dePessoas Anteriormenteem D esvantagem (PAD) diretoras de companhias públicas cresceu de 14 (1,2\%) em 1992 para 438 (13\%) em 2002, mas o número de diretores executivos PAD permaneceu muito pequeno (PCAS, 2003, p. 41) .

$\mathrm{H}$ á numerosos indícios ${ }^{10}$ de que o partido governante teve que recuar no tocante ao EEN em virtude das críticas persistentes e até mesmo de sua condenação por parte, entre outros, de seus próprios aliados no Partido Comunista da África do Sul e no Cosatu, bem como por proeminentes simpatizantes do Congresso $\mathrm{N}$ acional Africano e por intelectuais públicos como M oeletsi $\mathrm{M}$ beki e o renomado dramaturgo e escritor Zakes $\mathrm{M} \mathrm{da}{ }^{11}$. U ma avaliação abrangente do que foi conquistado é difícil, tendo em vista o grande número de variáveis envolvidas. No entanto, não há dúvida de que as fileiras da "classe média negra" foram inchadas nos últimos dez anos a ponto de (em 2004), com base em critérios razoáveis relativos à renda, poder ser dito que 1,5 milhão de pessoas "negras" ingressou nela desde 0 final dos anos de $1980^{12}$. Ao mesmo tempo, todos concordam que a grande mai oria dos pobres não ganhou praticamente nada com a legislação de ação afirmativa ou com o empoderamento econômico dos negros. M esmo conservadores negros, membros do establishment, começaram a alertar para o fato de que é essencial que os benefícios da ação afirmativa, do EEN e das estratégias afirmativas de aquisição não sejam vistos atingindo apenas "uns poucos escolhidos" ${ }^{13}$. O fracasso na distribuição de benefícios e benesses pelo poder estatal para todas as classes da população tem sido criticado mesmo por instituições internacionais, como o Programa para o D esenvolvimento das N ações U nidas (U N D P), que não pode ser acusado de preconceito contra o governo ${ }^{14}$. U m(a) editor(a) da Business D ay che gou ao ponto de desafiar, com base no que ele(a) acredita estar justificadamente criticando, o governo por não oferecer oportunidades iguais para todos os sul-africanos, escrevendo sem meias-palavras:

Se vamos dar início a uma economia de livre mercado em uma sociedade tão desigual em sua riqueza, então temos que encontrar um modo muito inteligente
9. Não discutirei aqui alguns detalhes de intrigasesubterfúgioscorporativos pelos quaisa retribuição clássica tornou-se a vergonha dos agentes econômicos da África do Sul. A concessão de uma "eqüidade cosmética” por empresas de proprietários brancos para tornar visíveis "empreendedores" negrosnão tem relação com o empoderamento negro, como quer queo definamos 0 ministro das Finanças posicionou-se de modo firme contra tais práticas, mas é evidente o dilema vivido por capitãesdaindústria eproprietáriosdecapital que desejam obedecer à legislação quando reclamam, ainda que com outras intenções, quea necessidadedascomplexas estruturas de empoderamento que estão criando é determinada pelo fato de terem que "priorizar o empoderamento em vista da inexistência de capital negro" (Rose, 2004, p. 1). O sherdeirosbrancosdo desenvolvimento capitalista na África do Sul estão tão desesperados que, desde 2001, vêem publicando anualmenteo Thelittleblack book (Livrinho negro), descrito como "referência 
essencial sobre o conjunto do capital intelectual do qual podem ser gerados os atuais efuturos líderes da nação" (Financial M ail, 2004, p. 1). O shomenseasmulheresdessecompêndio, algunsdosquaissesentiriam desconfortáveisao se verem nessa augusta coleção, são considerados os principais impulsionadores, reais ou potenciais, do empoderamento negro, epontosdere ferênciavitaisparaaclassecapitalista entrincheirada.

10. Ver, entre outras, as recentes manifestações do presidente $\mathrm{M}$ beki e do ministro do TrabaIho, M embathisi M dladlana, arroladas na bibliografia.

11. M D A (2004) expressa a visão de muitas pessoas em seu artigo "Suffering in the wake of black empowerment".

12. Cf. Bisseker (2004, p. 19), quediscutecom certo detalhe a questão da definição de "classe média" na África do Sul. 0 trabalho recente de Schlemmer (2005) questiona os números dramáticos ostentados pelosmeiosdecomunicação populares. de fazer os pobres sentirem que seu sofrimento vale a pena. A redistribuição tem que ser garantida. M as como fazer isso sem mudar o jogo todo? (Business D ay, 24 de janeiro de 2003, grifo do autor).

Tendo em vista o contexto geopolítico no qual ocorre a transição para uma democracia liberal na África do Sul, a política econômica do EEN é, em minha opinião, terreno para uma contestação genuína. Como socialista, não tenho dúvidas sobre minha posição a esse respeito, como manifestarei quando discutir estratégias alternativas e possíveis às que estão sendo implementadas pelo governo da África do Sul no presente.

Algumas das melhores mentes no governo ou próximas a ele começam a se perguntar se já não é hora, mais de dez anos após as primeiras eleições democráticas na África do Sul, de pôr um fim às políticas de ação afirmativa, de aquisição preferencial e empoderamento econômico dos negros em sua definição mais estreita. 0 mais destacado defensor desse ponto de vista tem sido o professor Vincent M aphai, cientista político, ex-presidente da South African Broadcasting Corporation e atual presidente da BH P Billiton AS.

Para ele, a ação afirmativa é um meio, não um princípio. Por ser um direito reparador, retira sua validade de um sistema injusto e desigual. $\mathrm{N}$ a medida em que este muda, torna-se cada vez menos necessária. Em outras palavras, políticas baseadas na raça só são aceitáveis como um mecanismo temporário para o renivelamento. Alcançados seus objetivos, deveriam ser descartadas (cf. Brown, 2004, p. 21).

$\mathrm{N}$ ão chega a ser surpreendente que essa seja uma opinião minoritária entre a classe média negra em geral e entre os empresários negros em particular. Porta-vozes do governo opõem-se invariavelmente a esse tipo de argumento e, como resultado, a polêmica iniciada pelas opiniões largamente difundidas de $M$ aphai reduziu-se à proverbial tempestade em copo d'água. A questão fundamental que colocara, ou seja, a do caráter finito das políticas de ação afirmativa, não desaparecerá, por certo. Sua lógica cristalina começará a penetrar na consciência dos responsáveis por decisões, assim que os mercados econômicos começarem a registrar tendências negativas oriundas da implementação de regras e regulamentos antiprodutivos. Q ue já não o tenham feito de modo espetacular é, paradoxalmente, um dos indicadores mais esperançosos da paisagem estatística do país. 
E ssas são al gumas das mais importantes questões relativas à estratégia de 14. Ver N ewmarch (2004). empoderamento negro e de ação afirmativa na África do Sul pós-aparthed. Essa análiseapontou, no mínimo, para os temas quedevem ser urgentemente enfrentados para se evitar as contradições potencialmente diruptivas que essa política pode produzir. D e meu ponto de vista, a questão mais importante e, na verdade, historicamente decisiva de toda a temática da ação afirmativa e do empoderamento econômico dos negroséa inevitável perpetuação das identidades raciais queestá explícita em sua própria conceitual ização equeéevidentena expressão cotidiana dessa política em termos práticos. Ao adentrar essa discussão, quero deixar claro desde o início que nossas afirmações sobre a situação da África do Sul só podem ser transpostas para outros contextos nacionais com as devidas reservas e com a consideração de suas diferentes dinâmicas históricas e sociais. $\mathrm{N}$ a verdade, uma de minhas objeções a essa política, tal como foi implementada, é precisamente o fato deque dependemuito estreitamente da reprodução deestratégias discursivas esocioeconômicas produzidas no contexto dos Estados U nidos, que, em alguns casos, foram já abandonadase, em outros, levaram a claros becos sem saída.

Dito isso, quero deixar inequivocamente registrado que a política de ação afirmativa ede empoderamento econômico negro tal como implementada hoje é um erro desastroso eque lamentaremos o dia em que o povo da África do Sul foi levado, querendo ou não, a aceitá-la. Por que insisto tanto nessa posição política, que definitivamente não é popular na África do Sul? A resposta é simples, porém difícil de pôr em prática, precisamente em virtude da postura racial arraigada, que desfigurou tanto a construção como a percepção da realidade pela ampla maioria dos sul-africanos.

$M$ eu ponto de partida é o seguinte: mesmo sem negar a importância da contestação ou das ações de grupos subalternos, o Estado - em especial o Estado democrático - exerce uma prerrogativa paradigmática, ou seja, fixa o modelo pelo qual as identidades sociais são modeladas. $M$ arx expressa essa óbvia constatação da seguinte maneira:

As ações estatais tiveram grande importância na formulação dos modelos das modernas relações raciais. Por todo lugar e sempre que Estados estabeleceram regras formais de dominação segundo distinções raciais, o racismo foi reforçado... O nde a dominação racial não foi codificada pelo Estado, os problemas e conflitos em torno da raça se diluíram... (1998, p. 267) 
15.Para uma análise completa desse tema, ver Alexander (2004).

16. Por mais banal que soe, bastaria, na maioria dos casos, determinar que pessoas foram classificadas da mesma ma neira que haviam sido sob o aparthed ou, no caso deindivíduosmuito jovens, como seus pais o foram. No mínimo essa abordagem poria em questão as categoriasraciaiseconferiria aosindivíduosapossibilidade de se distanciarem dessas categorias.

\section{Teste de "raça" rea-} lizado pelo regime do apartheid para verificar a identidade racial das pessoas. A penas aquelas cujo cabelo não prendesse o lápis eram consideradas brancas (N.T.).
No caso da África do Sul pós-apartheid, seria obviamente absurdo falar de uma "dominação racial", ao menos por pessoas "negras" . 0 importante, no entanto, é que, em virtude desse ponto de vista sociológico, qualquer governo moderno, mas em particular um que estejaà frente de uma sociedade claramente em transição, na qual podemos supor que as mentes das pessoas, em termos gerais, estão mais abertas para aceitar atémesmo mudanças radicais, deve estar extremamente atento ao modo previsível como as determinações estatais podem limitar, ou al ternativamentelibertar, a imaginação dos cidadãos. Sem entrar em detal hes neste artigo ${ }^{15}$, gostaria de apresentar algumas proposições a respeito, no mínimo como peças para um debate.

Em primeiro lugar, não é necessário usarmos as categorias raciais do passado com a finalidade de aplicar políticas de ação afirmativa. N o contexto sul-africano, tendo em vista o fato demográfico de que há uma maioria negra no atual estágio de evolução da consciência cultural da população, a estratégia seria igualmente efetiva e focalizada com maior precisão no nível dos beneficiários individuais se grupos por classe ou renda fossem usados como o principal impulsionador do programa. A ampla área de intersecção entre "raça" e "classe" na África do Sul possibilita essa abordagem. Além disso, possibilitaria a todos os indivíduos em desvantagem econômica, independentemente da cor, beneficiar-se dos programas derivados dessa estratégia.

Em segundo lugar, a experiência humilhante da autoclassificação racial e a reativação completa da parafernália técnica dos ideólogos raciais do apartheid, necessárias para a identificação dos cidadãos em termos de sua "raça", seriam eliminadas. N os casos em que fosse necessário o acompanhamento de mudanças em termos demográficos - pois tal mudança é possível no curto e no médio prazos - , não haveria problemas para encontrar outros modos de registrar o fato e/ ou o ritmo da alteração ${ }^{16}$. Em lugar de submeter os burocratas à ingrata tarefa de comportar-se como seus predecessores do apartheid, sem fazê-los empregar "técnicas" como o "teste do lápis"17 ou o teste lingüístico da pronúncia de termos-chave, o monitoramento das mudanças requeridas tornar-se-ia uma prática abrangente e aceitável. D a mesma maneira, poderíamos usar as habilidades lingüísticas das pessoas para promover reparação de modo orgânico. N enhum servidor público, por exemplo, deveria ser nomeado a menos que ele/ ela demonstrasse certo grau de proficiência em uma ou mais línguas nativas africanas. Em suma, precisamos estudar em detalhe cada uma das áreas nas quais a ação reparadora deve ser aplicada para podermos identificar as causas reais 
da desvantagem experimentada pelos respectivos indivíduos ou grupos. Empregando o critério simplificador de "raça", não proporcionamos ape nas vantagens à classe média negra contra a classe trabal hadora, mas enraizamos - o que deveríamos evitar - as mesmas categorias raciais que sabotam a possibilidade de atingirmos uma democracia verdadeiramente não racial na África do Sul.

Em terceiro lugar, sem negar minimamente a tenacidade das identidades sociais, deveria ser claro ao menos para os servidores públicos e lideranças políticas mais atilados que, se estamos de acordo que identidades são construídas $^{18}$ e não dadas, deveríamos aproveitar todas as oportunidades para conduzir nosso povo em direção à concretização dos valoresnão raciais sacramentados na Seção 1(b) da Constituição da África do Sul. 0 reconhecimento de diferenças superficiais não deveria ser, nem mesmo potencialmente, um instrumento de marginalização ou exclusão de nenhum indivíduo ou grupo de pessoas. Essa é a essência de uma abordagem não racial para promover a unidade nacional, a integração e a coesão sociais. Em sentido contrário a esse ponto de vista, quase todas as atuais medidas de ação afirmativa tendem a solapar tal integração e coesão. E, para dizer com todas as letras, não é preciso fazer nenhuma concessão aos beneficiários do apartheid e do colonialismo. 0 princípio da reparação histórica continua a ser a estrela-guia de todas as políticas de transformação social na atual fase da história da África do Sul.

Governo elíderes do Congresso $\mathrm{N}$ acional Africano começam a questionar cada vez mais a necessidade de cotas raciais nos vários setores em que se promove a transformação justamente porque têm percebido o perigoso potencial de divisão das ações afirmativas tal como vêm sendo implementadas ${ }^{19}$. Recentemente, o ministro da $D$ efesa e presidente nacional do Congresso N acional Africano, M osiuoa Lekota, bem como o ministro do Esporte, $M$ akhenkesi Stofile, manifestaram-se incisivamente contra as cotas, respectivamente, nas forças armadas e nas seleções nacionais. Em uma entrevista coletiva, Lekota abordou sem reservas o tema como sendo de importância nacional:

Q uando deixaremos de ser africanos, "coloureds", indianos, e assim por diante, para sermos (apenas) africanos?... Esta questão da representatividade [...] em algum momento devemos encará-la e dizer que não há indianos aqui, indianos vivem na Índia... E as pessoas chamadas de "coloured" [...] são provavelmente mais sul-africanas que o resto...
18. Como afirmamos anteriormente, a tenacidade dasidentidades sociais deriva, com efeito, do fato de que a maioria dos indivíduos não se dá conta da dinâmica socioistórica que cria os espaçosidentitários ocupados por cada um desses indivíduos.

19. H áum dito memorável desse potencial, embora em si mesmo pouco importante, supostamente difundido entreas pessoas declasse média definidas como "coloured". Em virtude do suposto tratamento preferencial dos candidatos "africanos" àsvagas nossetorespúblico eprivado, diz-se que reclamam deque, "antes, não éramos suficientemente brancos; agora, não somossuficientementenegros". 
20. A insistência de Le kota sobre esse tema pode dever-seatensões nas Forças Armadas $\mathrm{N}$ acionais (SAND F), cujos membros não se vinculam à legislação da ação afirmativa da mesma maneiraqueos servidores públicos comuns.
É evi dente que estou apenas apontando na direção de uma discussão muito mais profunda. 0 espaço disponível e a relevância para o tema geral deste ensaio são adequados para o que aqui sugeri, no entanto esse é um debate vital não apenas para nós, na África do Sul, mas para todaa aldeia global. U m desenvolvimento potencialmentesignificativo nessa área éo uso pelosjovens urbanos do termo "umlungu" (homem ou mulher brancos) para designar indivíduos negros ricos. Combinando dessa maneira "raça" e "classe", eles, paradoxalmente, estão dando início ao processo dialético de des-vincular "raça" de "classe"20.

Poderíamos assim nos perguntar: há outro caminho? Será possível, na ausência de uma revolução social, como aquela de um país como C uba, que começou a transformar as práticas de discriminação e de preconceito raciais, redistribuir poder, riqueza, capacidades e conhecimento sem empregar as categorias discriminatórias herdadas, raciais e muitas outras, que caracterizavam a trama social da África do Sul do aparthei d? A resposta cabal é sim. Lembremo-nos, contudo, que mesmo em Cuba, a despeito das inegáveis transformações radicais que lá ocorreram, o preconceito racial continua a desfigurar a face da sociedade. U ma das irônicas razões desse fato é que, por meio da promoção de uma ética de desconsideração da cor entreas gerações pós-1959, a raça não apenas se tornou invisível, fazendo com que o preconceito racial sobrevivesse de forma reprimida ou disfarçada, mas tornou-se igualmente, em público, um tema tabu. D evemos aprender com a experiência de outras sociedades, se não queremos repeti-las. Seja o que for que façamos, não devemos ter medo de encarar aberta e publicamente temas como racismo e preconceito racial.

Acredito que devemos repensar os modos pel os quais estamos tentando produzir aquilo que denominamos de reparação histórica para quenão perpetuemos inadvertidamente identidades raciais. Sandile D ikeni lembrounos, em sua coluna de 10 de junho de 2004, que o discurso da ação afirmativa foi transplantado para cá a partir de um contexto muito diferente, o das lutas pelos Direitos Civis nos Estados Unidos. $\mathrm{N}$ ão lidamos aqui com a síndrome de uma minoria. O s sul-africanos negros, aqueles que eram oprimidos e explorados na ordem social anterior por conta da cor de sua pele, constituem a maioria da população da África do Sul. Eles possuem o poder cívico de pleitear insistentemente novos modos de distribuir os recursos obtidos pelo Estado a partir das atividades produtivas de todos os cidadãos do país, e, em teoria, por meio do controle parlamentar, podem reformular o modo como nos identificamos, mesmo que esse processo demande não 
apenas décadas, mas gerações. A questão central em pauta é a da relação mais perfeita entre nossa identidade (sul-africana) nacional e todas as demais identidades subnacionais.

\section{A alternativa socialista}

A África do Sul continua a ser uma terra de boas esperanças, mesmo em relação ao desafio posto à espécie humana de encontrar formas de vida social nas quais superstições como "raça", e muitas outras, não desfigurem a vida das pessoas. Além das alternativas discursivas sugeridas acima, ficou claro paramuitos sul-africanos pensantesque outras estratégias, menosarriscadas, são possíveisno campo daeconomia eda sociedade. Por exemplo, um economista como Terblanche(2002), na quarta parte de seu trabal ho sobrea desigualdade na África do Sul, defende uma mudança radical de paradigma em direção ao que denomina de "versão social-democrata do capital ismo democrático", que confia menos na premissa neoliberal de que todo crescimento provém do setor privado erequer um papel muito maior do Estado no impulso transformador. D elineia um cenário de pesadelo, no qual a tendência para um enclave capitalista de primeiro mundo continuará ininterruptamente por maistrinta anos, produzindo uma burguesia muito menor emais rica quehoje, tanto em termosabsolutos como relativos, eum "lumpemproletariado" na periferia (cf. Terblanche, 2002, p. 464) muito maior e mais pobre. Allister Sparks (2003), um dos jornalistas mais conhecidos e mais sérios do país, defendeigualmenteuma ordem liberal-democrática mais responsável socialmente. Com base na abordagem do economista peruano H ernando de Soto e de outros "terceiro-mundistas", também propõe um programa de trabalhos públicos conduzidos pelo Estado e inspirados no $\mathrm{N}$ ew $\mathrm{D}$ eal de Roosevelt, bem como a valorização de transações econômicase formas de propriedade tradicionais, como as que existem entre pessoas comuns no assim chamado setor informal.

Aqueles que, como Sparks e Terblanche, procuram um caminho alternativo para o desenvolvimento dentro do capitalismo, uma forma de capitalismo com face humana, necessariamente se voltam contra a lógica do sistema tal como se desenvolveu historicamente, em particular na fase atual de "globalização" neoliberal agressiva e de rapina. Buscam al go que vale a pena. No entanto, aqueles que, como nós, não acreditam que esse sistema possa ser aperfeiçoado por reformas pontuais devem perseverar na proposição da alternativa socialista, que se baseia em um conjunto de valores dis- 
tinto, mesmo que hoje em dia abaixo da linha do horizonte. Temos simplesmente que perseverar em expor as contradições do sistema, dar início e apoio às reformas democráticas mais radicais, ou seja, àquelas que visam a fortalecer a posição e a segurança dos pobres no campo e nas cidades, e, ao mesmo tempo, perseverar o que Friedrich Schiller, autor da 0 de à alegria musicada por Beethoven, chamava de "a educação estética da espécie humana". Espero que me perdoem por sugerir que, ao lado de alguns outros países, a África do Sul pós-apartheid éo lugar onde o currículo dessa educação está sendo formulado.

Referências Bibliográficas

Adam, H .; Slabbert , F. \& M o odley, K. (1997), Comrades in business: post-liberation politics in South Africa. Cidade do Cabo, Tafelberg.

Alexander, N . (2004), Brown vs. board of education: a South African perspective. Praesa

O ccasional Paper, n. 20. Cidade do Cabo, Praesa, University of Cape Town.

Anônımo. (2003), "Empowerment puzzle". Bussiness Day, 20 jan.

Bisseker, C. (2004), "The black middle class". Financial M ail, 8 out.

Brown, S. (2004), "Two roads to power". M ail and Guardian, 2 a 8 out.

C ARTer, C. (2004), "Lekota questions affirmative action”. ThisD ay, 2 jun.

FINANCIAL M AIL. (2004), The little black book. Joanesburgo, BDFM.

GunNing, E. (2004), "Stofile an SA sport: weg met kwotas!". Rapport, 6 jun.

Laurence, P. (2004), "Senior members of AN C voice alarm over BEE". Sunday Independent, 10 out.

M ARX, A. (1998), M aking race and nation: a comparison of the U nited States, South

Africa and Brazil. Cambridge, UK, Cambridge University Press.

M вEKI, T. (2004), State of the nation address by the president of South Africa, Thabo

$M$ beki the joint sitting of the houses of the parliament. Cidade do Cabo, 21 maio. M DA, Z. (2004), "Suffering in the wake of black empowerment". ThisD ay, 28 abr. M d LAd LANA, M . (2004), "O pening address by the honourable minister of labour,

M P, M embathisi M dlaladlana, at the $2^{\text {nd }}$ Bankseta International Conference". Pretoria, D epartamento do Trabalho.

M pofu, D. (2003), "M oeletsi M beki gives ammunition to the opponents of true change". Sunday Times, 17 ago.

N CUBE, T. (2004), "Empower the majority, not a select few". Sunday Times, 10 ago. N EWMARCH , J. (2004), "UNDP says affirmative action has increased individual inequalities". ThisD ay, 16 jul. 
N YATI, M . (2004), "Admitting to racism is vital first step firms must take". Business Day, 11 out.

PC AS (Policy C o-ordinating and Advisory Series). (2003), Towards a ten year review: synthesis report on implementation of government programmes. Pretoria, The Presidency.

Petros, N . (2003), "From apartheid beneficiary to defender of 'poor'". Business D ay, 27 jan.

RoSE, R. (2004), “M enuel hits out ay çosmetic' equity deals”. Business D ay, 10 nov. Schlemmer, L. (2005), "Black advancement: hype outstrips reality". Focus, 39, $3^{\text {rd }}$ quarter, pp. 2-5.

Smith, A. (2004), "Ras-idee 'begalik', sê Brian". Rapport, 24 out.

Sparks, A. (2003), Beyond the miracle: inside the New South Africa. Joanesburgo/ Cidade do Cabo, Jonathan Ball Publishers.

Terblanche, S. (2002), A history of inequality in South Africa 1652-2002. Pietermaritzburg, University of $\mathrm{N}$ atal Press.

\section{Resumo}

Cidadania, identidade racial e construção nacional na África do Sul

Este artigo examina a relação entre a ação afirmativa, tal como aplicada na África do Sul pós-apartheid, e a concomitante perpetuação das identidades raciais formadas ao longo da história colonial e de apartheid do país. 0 autor problematiza a situação e sugere um curso de ação alternativo, menos perigoso e gerador de divisões. Palavras-chave: Cidadania; Identidade racial; África do Sul.

\section{Abstract}

Citizenship, racial Identity and nation building in South Africa

This article examines the relationship between affirmative action as applied in postapartheid South Africa and the concomitant perpetuation of racial identities that were shaped by the colonial and apartheid history of the country. It problematises this state of affairs and suggests an alternative, less divisive and dangerous course. Keywords: Citizenship; Racial identity; South Africa.

N eville Alexander é diretor do Praesa (Project for the Study of Alternative Education in South Africa). Email: nalexand@huma nities.uct.ac.za. 